\title{
EI TRATAMIENTO PERIODÍSTICO DE LAS NOTICIAS RELACIONADAS CON LOS VIRUS DEL DENGUE Y ZIKA EN LOS MEDIOS DIGITALES DE HONDURAS (2010- 2017)
}

\author{
Mg. Laura Andrea Aceituno Castillo \\ Universidad de Valencia, Valencia, España \\ andreaceituno12@gmail.com
}

Recibido el 27 de octubre de 2018

Aceptado el 5 de diciembre de 2012

\begin{abstract}
Resumen
En 1979, se identificó la primera epidemia de dengue en Honduras. En 2010, las autoridades sanitarias y gubernamentales hondureñas decretaron lo que sería la quinta epidemia que afectaba a la población. Cinco años más tarde, una enfermedad emergente llegó al continente americano: el zika. Las entidades internacionales como la Organización Mundial de la Salud y la Organización Panamericana de Salud extendieron la alerta a nivel latinoamericano, en especial a los países propensos por su situación geográfica, climatológica y situación socioeconómica. El objetivo del presente estudio es analizar el contenido de las noticias que se publicaron sobre los virus del dengue y zika en tres diarios digitales de Honduras (El Heraldo, La Tribuna y La Prensa) durante el período 2010-2017. La investigación se ha llevado a cabo con una muestra de documentos, seleccionada a través del método de la semana construida. A esta muestra, se le ha aplicado una ficha de vaciado de registros que contemplaba campos cuantitativos y cualitativos. Los resultados nos muestran el escaso abordaje de estas patologías desde el punto de vista de la difusión del conocimiento científico, así como desde el punto de vista de la agenda social. Se evidencia la nula especialización periodística en el marco del periodismo digital para la comunicación científica y temas de salud.
\end{abstract}

Palabras clave: Análisis De Contenido, Periodismo Científico, Dengue, Zika, Honduras. 


\title{
THE JOURNALISTIC TREATMENT OF THE NEWS RELATED TO DENGUE AND ZIKA VIRUSES IN THE DIGITAL MEDIA OF HONDURAS (2010-2017)
}

\begin{abstract}
In 1979, the first dengue epidemic in Honduras was identified. In 2010, the Honduran health and governmental authorities decreed what would be the fifth epidemic affecting the population. Five years later, an emerging disease came to the American continent: Zika. International entities such as the World Health Organization and the Pan American Health Organization extended the alert to a Latin American level, especially to those countries most vulnerable given their geographical, climatological and socioeconomic situations. The objective of this study is to analyze the content of the news that were published on the dengue and zika viruses in three digital newspapers of Honduras (El Heraldo, La Tribuna, and La Prensa) during the 2010-2017 period. The research has been carried out with a sample of documents selected through the constructed week sampling method. This sample has been applied in a spreadsheet that included quantitative and qualitative fields. The results show us the scant coverage of these pathologies from the point of view of diffusion of scientific knowledge, as well as from the social agenda. There is evidence of the absence of journalistic specialization within the framework of digital journalism for science communication and health issues.
\end{abstract}

Keywords: Content Analysis, Scientific Journalism, Dengue, Zika, Honduras.

\section{Como citar este artículo:}

Aceituno, L. (2019). "El Tratamiento Periodístico De Las Noticias Relacionadas Con Los Virus Del Dengue Y Zika En Los Medios Digitales De Honduras (2010-2017)", en Perspectivas de la Comunicación, Vol. 12, nº1, pp. 9-35. 
Introducción

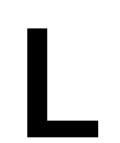

a 'Encuesta transversal sobre el ZIKV en Honduras' (ROSALES et al., 2017), determinó que, en general, el $50 \%$ de la población que participó en una encuesta levantada en 21 comunidades del país, señalaron que "no tenían suficiente información" sobre la enfermedad del zika. En donde, 8 de cada 10 personas sabían que esta enfermedad podía transmitirse por la picadura de un mosquito. El $2 \%$ y el $0.1 \%$ respectivamente, desconocían su propagación por relaciones sexuales y de una mujer embarazada a su feto.

La Organización Mundial de la Salud (OMS) recomendó la adaptación rápida del contenido y la información científica sobre esta patología en recursos apropiados para las poblaciones en riesgo. Sin embargo, este estudio logró obtener detalles sobre cómo la población tuvo conocimiento sobre esta enfermedad. La mayor parte señaló que fue a través de la radio y televisión. Otras fuentes eran familiares, amistades, y en muy raras ocasiones: el Internet o redes sociales. Aun así, los habitantes consideraron que no tenían suficientes datos sobre el zika.

En Honduras actualmente no se cuenta con un estudio estadístico que muestre un porcentaje de la población que tiene acceso a la información científica y temas de salud a través de los medios de comunicación. Es decir, no se cuenta con una red de trabajo que facilite la interacción de los productores del conocimiento científico con los tomadores de decisiones y que luego sean dirigidos a la ciudadanía (BERMÚDEZ-MADRIZ y MUSIER, 2011).

Las emergencias sobre salud pública colocan tensiones en las redes de información, y como tales, las comunicaciones de crisis efectivas se estiman como método esencial para una gestión de emergencia exitosa. Los medios de comunicación han jugado un rol importante en este proceso, sirviendo como un conducto para el flujo de la información entre los actores oficiales hacia el público en general.

Este subregistro de las enfermedades tiene un impacto directo en la salud pública. Los medios de comunicación colectiva en la difusión de la información sanitaria deben de cumplir el propósito de que la población reciba mensajes e informaciones educativas que permitan la sensibilización para que de este modo, se pueda de forma eficaz, adoptar conocimientos, actitudes y prácticas sobre la situación (RAMÍREZ et al., 2010 ; HAGEN et al., 2017; RAPPA et al., 2018).

\section{El conocimiento científico sobre los arbovirus: dengue y zika}


En 1839, Samuel Henry Dickson (1798-1872)1 publicó el artículo 'On Dengue: its history, pathology and treatment' (DICKSON, 1839) ${ }^{2}$ en el cual describe, en primera instancia, la localización de esta nueva patología en las islas Santo Tomás (Islas Vírgenes), luego su "desplazamiento" por el resto de las islas del Caribe y finalmente su llegada a las costas del continente americano.

Los autores MONTES y ESCALANTE (2010) mencionan respecto a las epidemias que han causado el dengue en las Américas y otras partes del mundo. Dichas causas, han surgido principalmente en países pobres donde las condiciones facilitan la propagación rápida y dificultan su control. La influencia de esta propagación e incidencia en los países dentro del trópico es en gran parte, por su condición climática.

El dengue es la enfermedad considerada por la OMS como la patología vírica "más importante" entre las transmitidas por los vectores Aedes. Corresponde a las Américas tener 18 de los 30 países con mayor incidencia del dengue a nivel mundial (Special Programme for Research and Training in Tropical Diseases and World Health Organization, 2009). Para el caso de Mesoamérica, se considera la región del continente -después del cono sur- que notifica la mayor cantidad de casos sospechosos de dengue, estos datos según el 'Plan Mesoamericano de gestión integrada para la prevención y control del dengue y chikungunya 2016-2017 Honduras' (2016).

El dengue en Honduras se presentó como epidemia a partir de 1978 con 13.400 casos en todo el país. Para 1987 se presentó la segunda epidemia calculándose unos 28.606 casos. Dos años después, en 1989, se presentó la tercera epidemia (en esta última no se pudo cuantificar el total de los casos). En 1991, se presentó la cuarta epidemia, siendo esta la aparición de los posibles primeros casos de dengue grave o hemorrágico (ZAVALA, 2010).

Durante el 2010 -el año epidémico más grave en Honduras- sufrió cerca de 67 mil casos con una incidencia de 1.016/100.000 habitantes. Fue el año con la letalidad más alta de la historia del país (MONTES y ESCALANTE, 2010). Esta patología ha afectado en los últimos años a este país centroamericano con un promedio anual de 34.678 casos, de los cuales, 2.723 correspondieron a dengue grave.

\section{Virus zika}

El 18 de abril de 1947 se desarrolló fiebre en Rhesus 766, un mono centinela en el programa de la Fundación Rockefeller que había sido colocado en una plataforma de árbol en el bosque Zika de Uganda donde se investigaba la fiebre amarilla selvática.

Dick $^{3}$, Kitchen y Haddow 4 describieron en el artículo 'Zika Virus. Isolations and Serologial Specificity' (1952) que en abril de 1947 se informó que la temperatura de Rhesus 766 era de 39.7 grados centígrados y un día después, se le registró un máximo de 40 grados

\footnotetext{
${ }^{1}$ Médico, escritor y educador estadounidense. Fundador del Colegio Médico de Carolina del Sur, Estados Unidos. ${ }^{2}$ The American Journal of the Medical Sciences vol. 3-4, hace referencia de que Dickson participó en estudios sobre el dengue cuando era profesor en el Institutes and Practice Medicine, en el Colegio Médico de Carolina del Sur. 3 W. A. Dick fue miembro de la National Institute for Medical Research en Londres.

4 S.F. Kitchen y A.J. Haddow fueron miembros de Division of Medicine and Public Health, The Rockefeller Fundation.
} 
centígrados. Después de 10 días, todos los ratones que se inocularon por vía intracerebral estaban enfermos. El resultado, un agente transmisible-filtrable, más tarde llamado "virus zika", se aisló de los cerebros de los ratones a principios de 1948 (HAYES, 2009).

El zika (ZIKV) también se aisló en los mosquitos Aedes africanus atrapados en el mismo bosque. Los estudios serológicos indicaron que los humanos también podrían estar infectados. Entre 1968 se notifica que el zika fue aislado en humanos en Nigeria y, durante 1971 y 1975 , en un estudio de laboratorio se encontró que el $40 \%$ de las personas evaluadas tenían anticuerpos neutralizados para ZIKV.

Debido a que el virus se ha propagado fuera de África y Asia, el zika se describe como un patógeno emergente. En 2007 se notificó el primer brote epidémico de importancia de la enfermedad ( 185 casos sospechosos y 49 casos clínicamente confirmados) la cual fue caracterizada por erupción cutánea, artralgia y conjuntivitis en la Isla de Yap en los Estados de Micronesia. Desde entonces, se han descrito diferentes casos en regiones tropicales de África y Asia. Para el 2013 se reportó la mayor epidemia de zika en la Polinesia Francesa con un registro de 28 mil casos (HAYES, 2009).

En América, los primeros casos confirmados se reportaron en la Isla de Pascua en Chile en febrero de 2014. En mayo de 2015, las autoridades de salud en Brasil confirmaron una transmisión autóctona del patógeno en el noroeste del país. Hasta octubre del mismo año -2015- el contagio había sido confirmado en 14 países del continente americano (NÚÑEZ et al., 2016).

No obstante, este virus tiene una similitud estructural a los virus del dengue, la fiebre amarilla, la encefalitis japonesa y el virus del Nilo Occidental. El virus es transmitido por el vector Aedes aegypti y Aedes albopictus. Asimismo, se han documentado casos de transmisión perinatal por transfusiones sanguíneas o por exposición a semen infectado. En humanos, el virus se ha detectado en sangre, saliva, orina, semen y leche materna (Evaluación rápida del riesgo de transmisión de enfermedad por el virus zika en España, 2015).

\section{La información como noticia, la divulgación de la ciencia y salud}

Un tema científico debe de competir para disponer de espacio y, dentro de esta "lucha por espacios", también coincide con otros aspectos. Entre estos destacan: la complicidad del potencial del titular, la relación entre periodista-jefe de sección, los acontecimientos externos sociales, culturales y las fuentes de la noticia (DE SEMIR, 1996). Sin embargo, no todo ha sido una noción de competitividad, también son evidentes muchas variables que determinan una ubicación de estas temáticas dentro de los medios de comunicación.

La aparición de la figura científica del periodista remonta a varios siglos atrás con las noticias referidas a contenidos científicos e invenciones tecnológicas. Estos eran años en donde se hablaba sobre la implementación de la energía eléctrica y del origen de las Exposiciones Universales, donde se mostraban los últimos inventos y los principales avances científicos (CALVO HERNANDO, 2011).

La situación comienza a relucir y tomar auge a finales del siglo XIX, específicamente en su dimensión aplicada, la ciencia empieza a ocupar un lugar habitual en periódicos y otras publicaciones similares (SANZ MERINO, 2011). A principios del siglo XX, el incremento de la complejidad científico-tecnológica requiere de un tipo de periodismo más especializado, 
una mayor preparación de conocimiento para quienes se dedicarían a divulgar sobre la ciencia.

Este aumento de la divulgación de las noticias científicas tuvo realce en los Estados Unidos en el siglo XX. El método para el acercamiento de la ciencia a la sociedad es -y ha sido en segunda instancia- a través de los medios de comunicación de masas. Primero, a través de los medios impresos y luego se viene evidenciando la inclusión a otros campos con el surgimiento de la televisión. Por último, a través de los medios digitales o transmedia, esto, describe SAMUDIO BARRIOS (2016), "como un mecanismo para socializar el conocimiento".

Con el inicio de la era del Internet, la forma para hacer y practicar el periodismo ha generado la transformación de sus métodos de transmisión del mensaje a través de la revolución de la multimedia. Dentro de estos cambios resalta la inmediatez y la innovación de las distintas formas de difundir los hechos y acontecimientos que son denominados como "noticia".

Durante los últimos años el aumento de las noticias científicas y médicas aparecidas en la prensa diaria ejerce presión sobre el mundo científico y médico siendo notoria la representatividad publicada. Sin embargo, viene a su vez la desinformación, el sensacionalismo -y en un extremo amplio casi fuera de control- la pseudociencia.

En general, los medios de comunicación se definen como instrumentos destinados a la información pública. Aunque en el ámbito especializado de las ciencias de la información y la comunicación, se destacan tres funciones clave: informar, entretener y formar. Como consecuencia, la salud de la población guarda una estrecha relación en el acceso y la utilización de la información, especialmente cuando son temas que afectan directamente a la calidad de vida y de los seres humanos (SANZ MERINO, 2011; MORENO CASTRO, 2009).

\section{Metodología}

La divulgación de la medicina y los temas sobre salud, conllevan a una interrogante respecto a las terminologías a utilizar en los procesos de redacción en las salas de prensa. El objetivo del presente estudio tratará de entender y captar qué ideas sobre estas enfermedades se transmitieron a la ciudadanía, en este caso, a los hondureños.

Para ello, utilizaremos la técnica del análisis de contenido en tres diarios digitales de Honduras (El Heraldo, La Tribuna y La Prensa) que en todos los casos transmitieron noticias durante las epidemias del dengue y zika. Como lo define RIBEIRO (2013), para comprender estos escenarios, los más comunes en la redacción de la noticia, es a través del análisis de contenido donde se determina "la información bruta, el proceso de edición y la publicación del contenido".

El análisis de contenido se utilizó en un principio como una técnica para la cuantificación de los materiales de comunicación, tales como la información de periódicos, revistas y programas de radio. Últimamente este procedimiento se empleó en diversos contextos y para comprender la amplia gama de finalidades de investigación (RIBEIRO, 2013). Los autores IGARTUA y HUMANE (2004), describen que esta es una técnica de investigación que permite descubrir el "génesis" de los mensajes mediáticos y así, conocer cómo está hecho y predecir su mecanismo de influencia. 
Con esta técnica, añade LÓPEZ NOGUERO (2002), que no es el estilo del texto lo que se propone analizar, sino las "ideas expresadas en él, siendo el significado de las palabras, temas o frases lo que intenta cuantificarse". Asimismo, se centra su búsqueda en los términos que hacen un conjunto en la comunicación $y$, por ende, se toma una determinación referente a cómo se ha sido transmitido el mensaje.

Por medio de este trabajo de investigación se propone conocer el cómo del tratamiento de la información periodística dentro de las noticias publicadas durante el brote epidemiológico del dengue y zika en tres medios de comunicación digital de Honduras antes mencionados. Esto en base a los datos emitidos por la OMS donde se señala que Honduras fue uno de los países a nivel de la región centroamericana en verse más afectado por los casos del dengue y zika.

Del mismo modo, se seleccionaron dichos medios de comunicación al ser de mayor antigüedad, mayor número de audiencia y mayor número de tirada a nivel nacional. También, se seleccionaron estos diarios debido a que sus publicaciones en su versión digital se encuentran en el rango de los años de estudio seleccionados. Estos son: El Heraldo ${ }^{5}$, La Tribuna ${ }^{6}$ y La Prensa ${ }^{7}$ entre los años 2010-2017.

Los medios de comunicación digital como objetos de investigación hoy en día son recursos accesibles y permiten recopilar sus datos con facilidad. Sin embargo, la gran cantidad de información que se divulga puede resultar ser una situación -compleja- para su recolección. Para una mayor eficiencia en el trabajo y realizar una representación válida del contenido, se trabajó con la técnica de construcción de semanas.

Esta técnica sobre el muestreo estratificado es la respuesta más convincente al problema de la variación sistemática del contenido en los medios de comunicación. A través de estudios se ha encontrado que las semanas construidas son adecuadas para representar una población (HESTER y DOUGALL, 2007).

La aplicación de la semana construida para esta investigación dio como resultado una muestra de 372 días. De este modo, si atendemos a la representatividad de esta muestra respecto al universo muestral, es decir, lo que suponen estos 372 días respecto a los 8.760 que correspondería a la totalidad del período de estudio ( 365 días por los ocho años, en los tres periódicos analizados). Esta muestra es representativa, con un $95 \%$ de nivel de confianza y un margen de error del $5 \%$.

Las noticias relacionadas con los virus dengue y zika que aparecían en la muestra ascienden a un total de 246 ítems. La técnica aplicada a estas noticias es el análisis de contenido, realizado de forma manual a través de una ficha de registros. Asimismo, una vez obtenidos los resultados, se realizan correlaciones entre los distintos factores analizados: el tema, el

\footnotetext{
${ }^{5}$ En su versión impresa se fundó en 1979, con tiradas a nivel nacional y con mayor presencia en la zona centro-sur. La representación de la audiencia (entre 18 a 44 años) en su formato digital es del $80 \%$. *No hay datos sobre los comienzos en su versión digital. Obtenido en: http://www.go.com.hn/diario-el-heraldo/

${ }^{6}$ En su versión impresa se fundó en 1976. Para el año de 1997 comenzó su versión digital publicando las mismas secciones de la versión impresa en formato PDF. *No hay datos sobre la representación de la audiencia. Obtenido en: https://web.archive.org/web/20130302040138/http://www.latribuna.hn/2012/12/og/la-tribuna-36-anos-alservicio-de-honduras/

7 En su versión impresa se fundó en 1964 en la ciudad de San Pedro Sula. La representación de la audiencia (entre 18 a 44 años) en su formato digital es del $86 \%$. *No hay datos sobre los comienzos en versión digital. Obtenido en: http://www.go.com.hn/diario-la-prensa/
} 
período temporal, especialización científica, fuentes consultadas, indicadores lingüísticos, actantes y encuadres.

Una vez definido el método de estudio y con los resultados obtenidos a través de las búsquedas de las noticias, con la ficha de registros para el análisis de contenido se evidenció los resultados de cómo estos cuatros medios de comunicación (El Heraldo, La Tribuna y La Prensa) divulgaron e informaron sobre estas patologías.

A su vez, se hizo una correlación sobre qué tema se abordó más y en qué año, qué medio tuvo una mayor especialización en cuanto a la divulgación, qué tema tuvo un abordaje más científico. También, se encontró qué actores se consultaron con mayor frecuencia, cuál fue el principal indicador lingüístico, actante y encuadre utilizado en su divulgación.

\section{Resultados}

\section{El total de publicaciones y temática:}

En el Gráfico 1 se puede observar que, de las 246 publicaciones distribuidas entre los tres medios de comunicación (El Heraldo, La Tribuna y La Prensa) durante los 8 años de análisis (2010-2017), el año que tuvo mayor número de publicaciones fue el 2016 con un 39\%; seguido del año 2014, con 30\%; y el 2015, con un 17\%. En los años 2017 y 2013, hubo un registro del $5 \%$ respectivamente, en el año 2010 se registró un 3\%. En el año 2011 un 1\%, y, para el caso del año 2012 hubo un o\% de publicaciones.

Los años con mayor número de publicaciones (2014 y 2016) están vinculados a que, en el primer año (2014) comenzó a aparecer el brote del chikungunya, enfermedad asociada al vector Aedes aegypti cuyos síntomas son similares a la enfermedad del dengue y que tuvo altos números de casos clínicos a nivel nacional. Aunque el brote del zika comenzó a diagnosticarse a mediados del año 2015 en América, en Honduras la incidencia de casos se presentó entre los meses de noviembre y diciembre del mismo año.

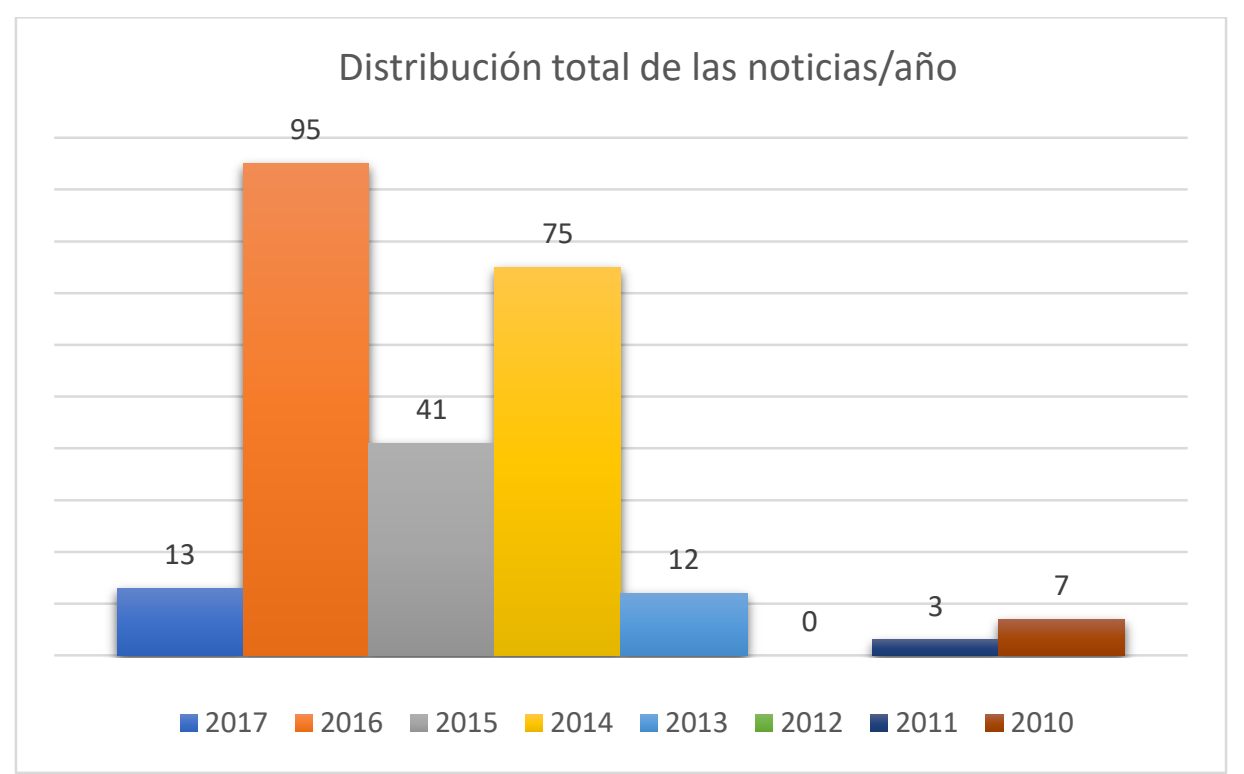

Gráfico 1. Distribución de publicaciones por año. Fuente: elaboración propia. 
Aunque la quinta epidemia del dengue registrada en Honduras se decretó en el año 2010, solamente se registró un $3 \%$ de publicaciones con un total de 7 noticias en todo el año, estas fueron informadas únicamente en el diario La Prensa según la semana construida. Lo mismo se puede apreciar en el año 2011 que tuvo solamente 3 publicaciones correspondientes al mismo medio de comunicación.

Para el año 2012 fueron nulas las publicaciones respecto al dengue en los tres medios de comunicación que coincidieran dentro y fuera de la semana construida.

La distribución de las publicaciones según el medio de comunicación y el año se pueden apreciar en el Gráfico 2.

Número de publicaciones según año y medio de comunicación

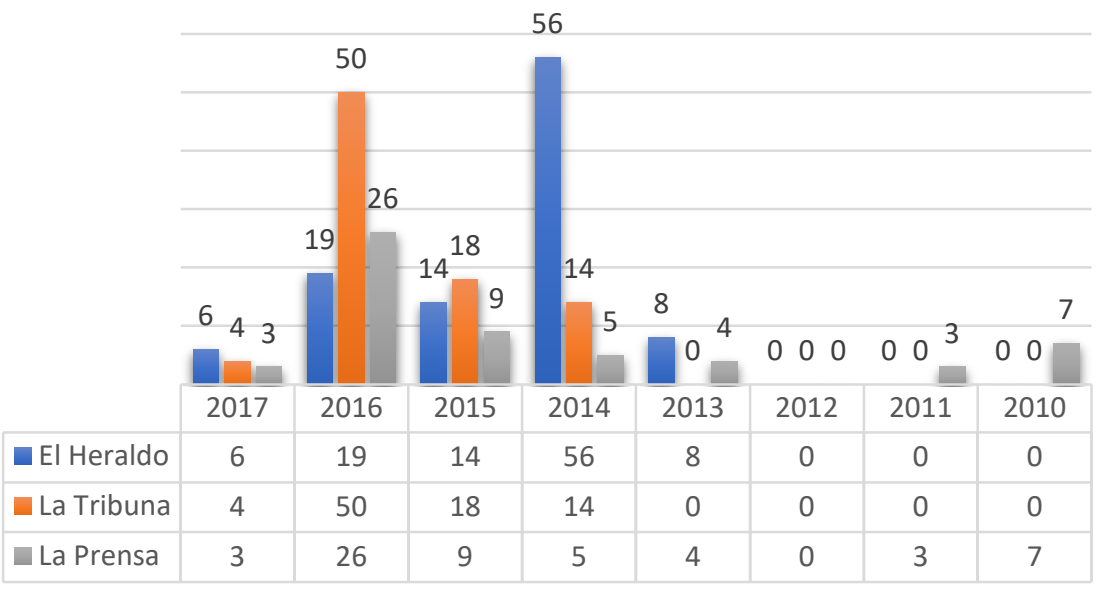

Gráfico 2. Distribución de publicaciones según el medio de comunicación y año. Fuente: elaboración propia.

Los temas definidos en la ficha de registros para el análisis del contenido fueron 'Dengue' y 'Zika'. La primera patología, por su antigüedad en el país, es la que tuvo mayor referencia de publicaciones alcanzando un $57 \%$ de apariciones como noticia. En comparación con el zika, que, a pesar de ser una patología "reciente", tuvo un impacto significante. Dentro de las publicaciones tuvo una representación del $43 \%$ en los años y medios analizados. En el Gráfico 3 se puede observar el número de publicaciones según el tema y medio de comunicación. 


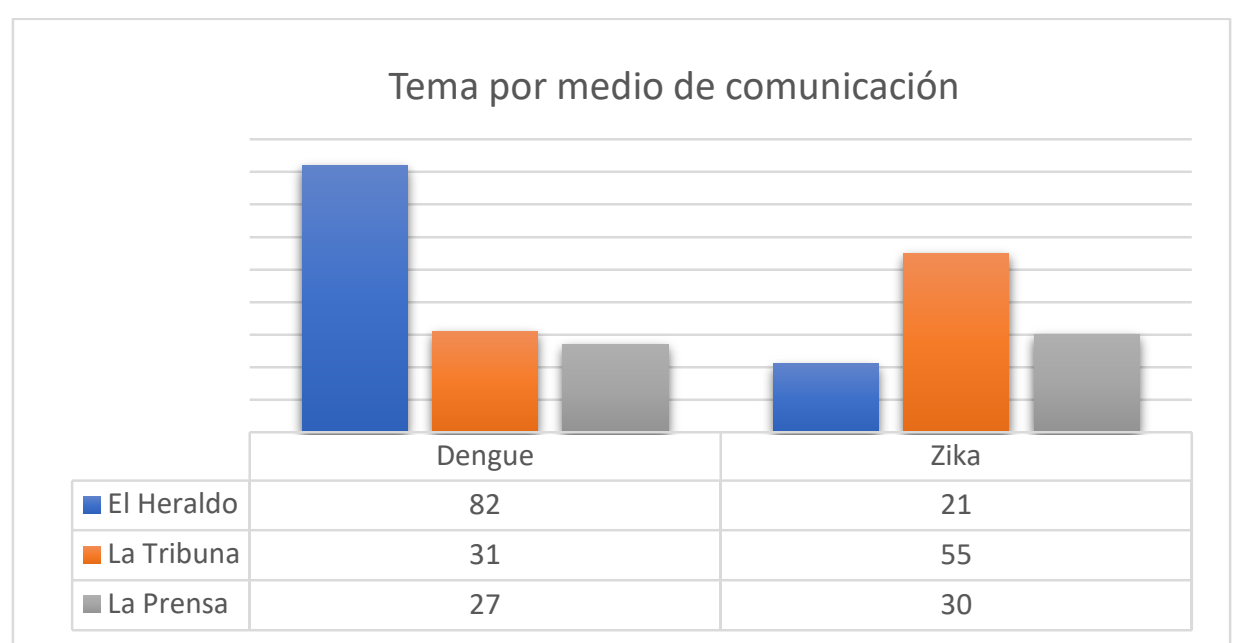

Gráfico 3. Distribución de temas por medio de comunicación. Fuente: elaboración propia.

Los encuadres: El encuadre o 'framing' se convierte en un rasgo definitorio de un texto, este incluye elementos y mecanismos pertenecientes a la variedad de los niveles comunicativos (OLIVER y PAÚLS, 2014). En el estudio realizado por los autores OLIVER y PAÚLS (2014), sobre el encuadre de los temas de salud, se identificó que los profesionales pueden abordar temas de salud desde tres puntos de vista o enfoques: el científico divulgativo que se aproxima al periodismo especializado en salud y ciencia; un enfoque político que refiere a los efectos positivos o negativos de ciertas iniciativas institucionales $y$, un enfoque de concienciación.

Dentro de este análisis de contenido, se logró deducir los encuadres o información abordada por los medios de comunicación según lo muestra la Gráfica 4. Se observó que, en efecto, la información que más se abordó fue en base a una 'información científica' que corresponde al $27 \%$ de las publicaciones. Estos temas, en su mayoría, estuvieron relacionados a información con datos estadísticos vinculados en primer lugar, al número de casos emitidos por la Secretaría de Salud. Y, en un número muy bajo, fueron temas sobre investigaciones científicas que emitieron medios internacionales.

El otro tema que abordaron los medios de comunicación fue el de 'atribución de responsabilidades' con un $23 \%$. Estas noticias consistieron en las declaraciones dadas en algunas ocasiones por las autoridades gubernamentales, la OMS y la OPS. Del mismo modo, los temas sobre 'conflicto/controversia' tuvieron un porcentaje del $22 \%$ de aparición en las publicaciones. Estos temas -conflicto/controversia- estuvieron fuertemente relacionados al incremento de casos de personas infectadas o afectadas por los virus.

También se pudo observar un sesgo de información respecto a las 'políticas sanitarias', con un $17 \%$, que en su mayoría de las noticias estuvieron relacionadas a las regulaciones dictaminadas por el gobierno en poder, seguido de las ordenanzas decretadas por las alcaldías municipales. El abordaje de temas sobre interés humano fue de un $7 \%, y$, un $2 \%$ de las publicaciones correspondió a las consecuencias económicas. Estas últimas tuvieron una orientación en aspectos como: reducción del turismo y falta de presupuesto en los hospitales para atender el alto número de pacientes afectados. 
En el Gráfico 4 se puede apreciar el número de publicaciones por medio de comunicación y los encuadres abordados.

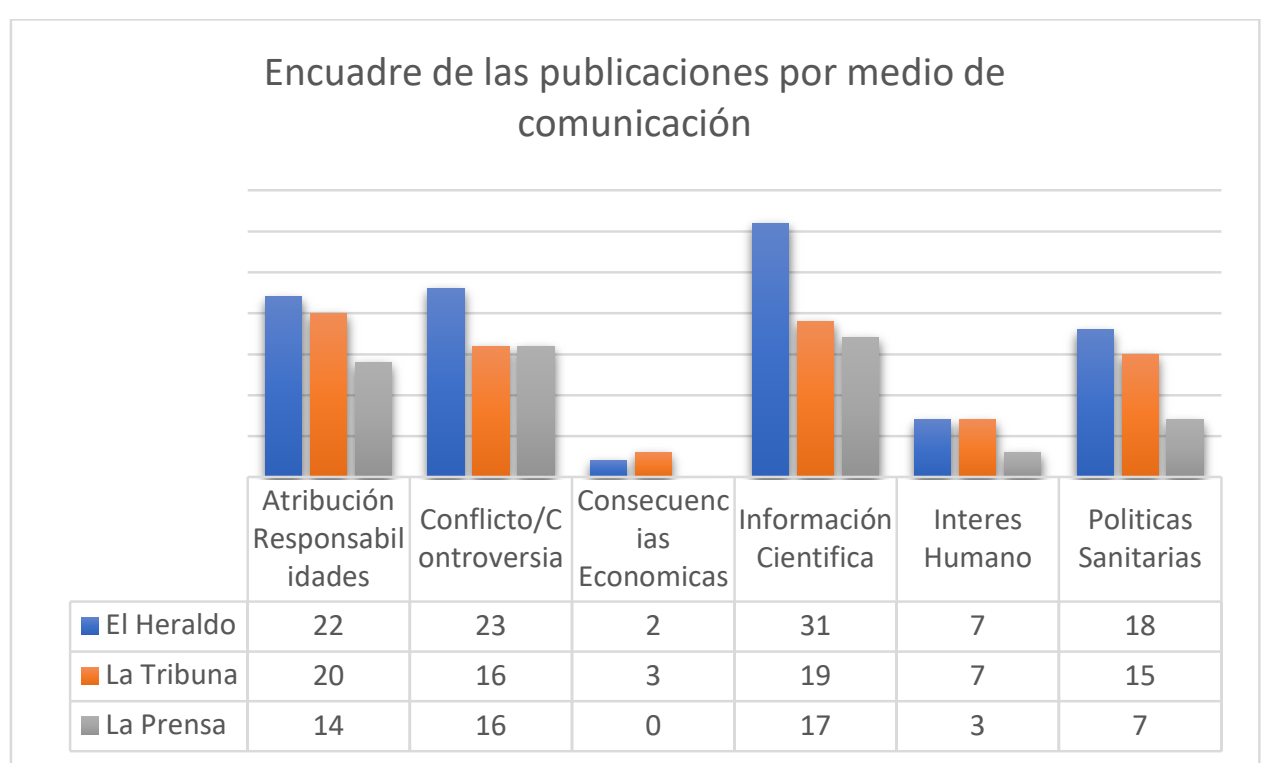

Gráfico 4. Encuadres utilizados según el medio de comunicación. Fuente: elaboración propia.

Dentro de estos encuadres, fue importante identificar de igual manera, quiénes fueron los principales actores en transmitir la información o el mensaje, ver Gráfico 5 . Estos datos se dividieron en: actores nacionales y actores internacionales. El Gráfico 6 muestra el número de publicaciones totales por medio de comunicación que corresponde el $54 \%$ de los actantes nacionales y el 10\% los actantes internacionales.

\section{Actantes por medio de comunicación}

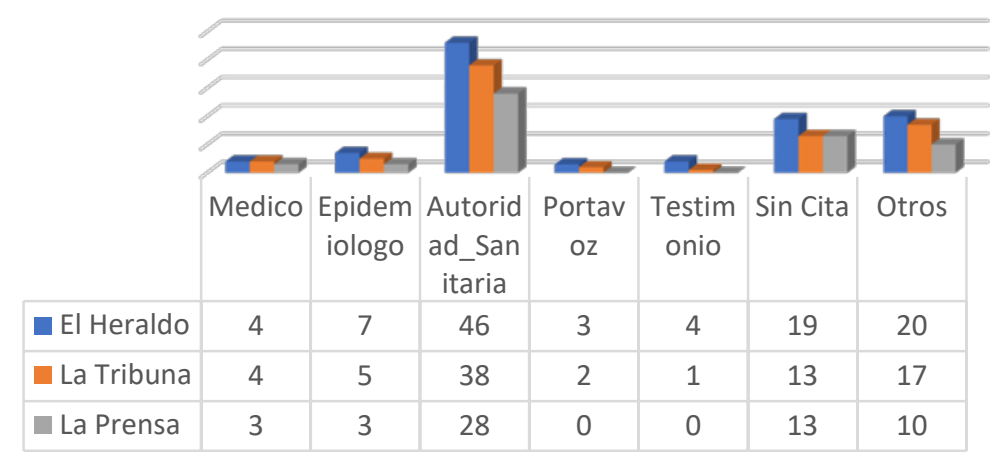

Gráfico 5. Distribución de los actantes por medio de comunicación. Fuente: elaboración propia 


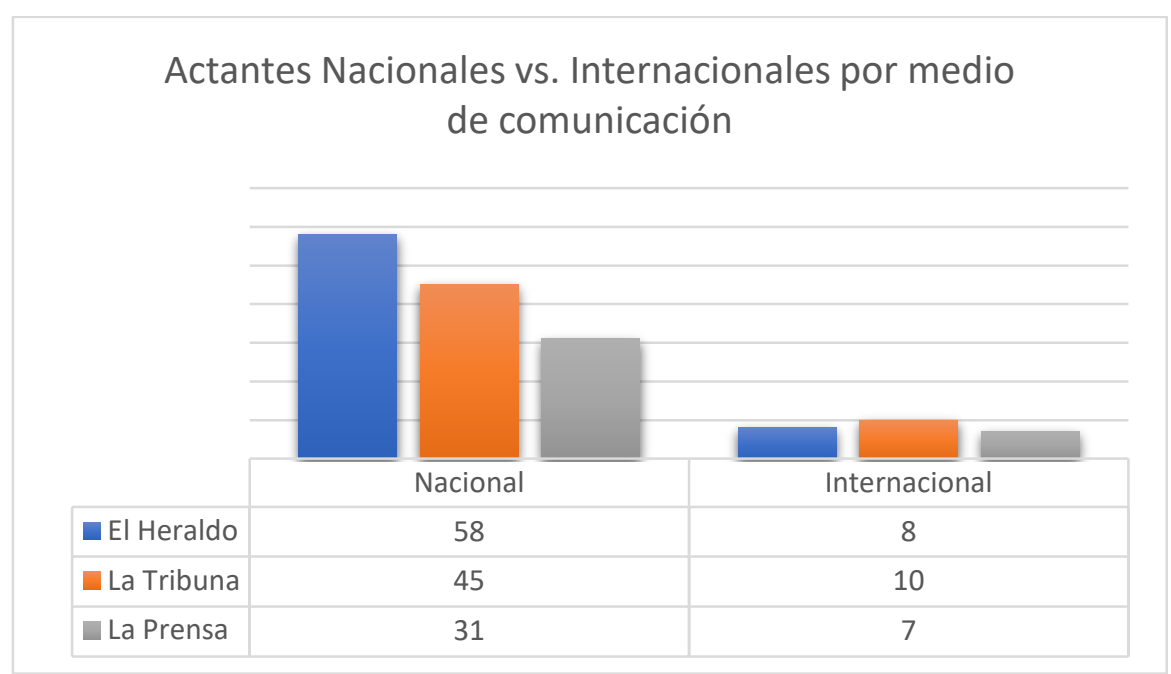

Gráfico 6. Distribución de actantes nacionales e internacionales por medio de comunicación. Fuente: elaboración propia.

En el Gráfico 7 se presenta la distribución de los actantes nacionales por medio de comunicación. Los datos muestran que los tres medios de comunicación, El Heraldo (43\%), La Tribuna (33\%) y La Prensa (23\%) consultaron en su mayoría información a las autoridades sanitarias, especialmente al ministro o viceministro de la Secretaría de Salud del país, siendo un total del $82 \%$ de las publicaciones. El otro actante, pero no tan frecuente, fueron las autoridades gubernamentales (presidente de la república y alcaldes) con una representación del $17 \%$ y, con un porcentaje bajo, el $2 \%$; fue la consulta a investigadores nacionales.

Un aspecto importante por destacar es que la representación de investigadores fue casi nula en los medios de comunicación analizados, a excepción de El Heraldo. Dentro de las publicaciones que correspondieron a las fechas de la semana construida, se lograron identificar solamente 2 noticias en donde se interrogó como fuente de información a investigadores nacionales respecto a la situación sobre estas patologías.

\section{Actantes Nacionales por medio de comunicación}

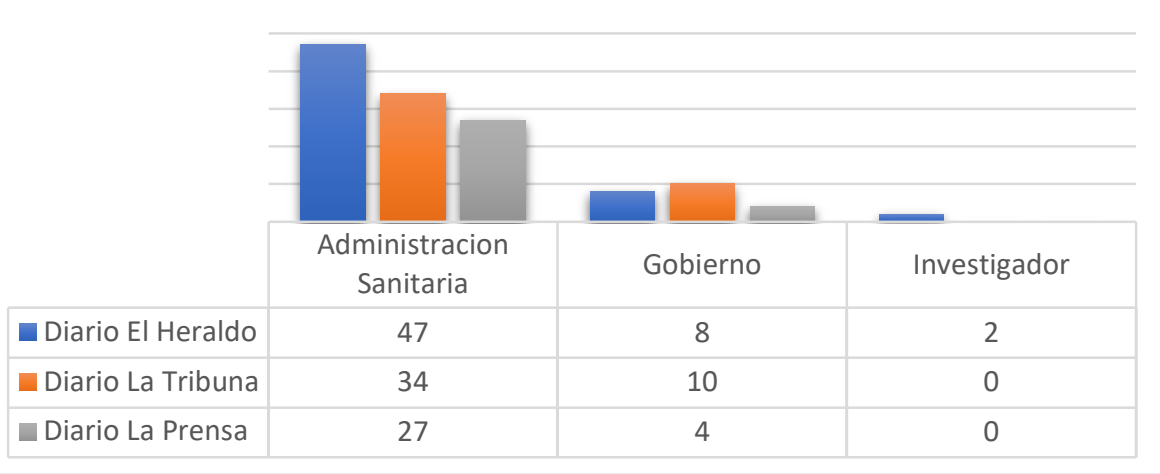

Gráfico 7. Distribución de actantes nacionales por medio de comunicación. Fuente: elaboración propia. 
Por otro lado, en el Gráfico 8 se muestra la inclusión de actantes internacionales. En este apartado destaca las declaraciones por parte de un gobierno extranjero, investigador, la OMS y la OPS. Como muestra el Gráfico 8, es evidente la nula inclusión de las opiniones internacionales respecto a estas patologías. En un marco general, los datos por medio de comunicación y la representación de actantes internacionales a nivel de porcentajes concentran en primer lugar por El Heraldo, con un 33\%; La Tribuna, con 38\% y La Prensa, con $29 \%$.

\section{Actantes Internacionales por medio de comunicación}

\begin{tabular}{|c|c|c|c|c|}
\hline & $\begin{array}{c}\text { Gobierno } \\
\text { Extranjero }\end{array}$ & Investigador & OMS & OPS \\
\hline Diario El Heraldo & 3 & 2 & 2 & 1 \\
\hline Diario La Tribuna & 1 & 0 & 7 & 1 \\
\hline Diario La Prensa & 4 & 2 & 1 & 0 \\
\hline
\end{tabular}

Gráfico 8. Distribución de actantes internacionales por medio de comunicación. Fuente: elaboración propia.

Sin embargo, se debe cuestionar que las publicaciones relacionadas con gobierno extranjero (33\%) e investigador (17\%), en su totalidad corresponde a noticias divulgadas por agencias de comunicación internacional y medios extranjeros. Destacando que estas contaban con la firma de la entidad divulgadora.

Los datos emitidos por la OMS (42\%) y la OPS (8\%), correspondían principalmente a las diferentes reuniones sostenidas con las autoridades sanitarias del país. Otras correspondían a los resultados de estudios realizados en diferentes países para fortalecer las políticas públicas, generar más campañas de prevención y el fomento de la educación sobre el riesgo que conllevan estas patologías.

La información científica: En el artículo publicado por ALMEIDA, et al., (2011) se describe aspectos comunes respecto a la divulgación de la ciencia y la situación compleja en la que se presentan los medios de comunicación en América Latina. Dicha problemática se ve reflejados en los resultados de esta investigación, donde se tomó en consideración el análisis de los temas sobre las patologías del dengue y zika en tres medios de comunicación digital de Honduras.

"Los periódicos latinoamericanos están más pautados por instituciones de investigación de países desarrollados, que por institutos de países vecinos -incluso, por institutos del mismo país- [...] señalan la dificultad de acceso a la información causada, por ejemplo, por las reducidas estructuras de asesoría de prensa en las universidades y centros de investigación" (ALMEIDA, et al., 2011:94).

Honduras no cuenta con una especialización en cuanto a la divulgación de la ciencia y temas sobre medicina. Como objetivo principal de esta investigación, se buscó analizar la 
información científica y su tratamiento en las publicaciones elaboradas sobre las patologías antes descritas. Como se abordó en el tema 'El conocimiento científico sobre los arbovirus: dengue y zika', es notable la evidente información histórica y clínica respecto a estas enfermedades a nivel global.

Al ser el dengue una de las enfermedades consideradas igual de antiguas como la viruela ${ }^{8}$, $y$, de igual forma, tras ser una de las epidemias más frecuentes en Honduras fue uno de los temas con menor abordaje en cuanto al encuadre sobre evidencia científica. Esto en base a los medios de comunicación utilizados como muestra y según la semana construida, abarcando únicamente el $40 \%$ de las publicaciones.

Por el contrario, la enfermedad del zika fue la que tuvo un amplio abordaje de información científica en los tres medios de comunicación abarcando el $60 \%$ de las publicaciones. Esto se puede relacionar a que, el virus del zika está vinculado a otras patologías neurológicas, sus síntomas son similares a los del dengue y la transmisión del virus ya no depende únicamente de la picadura del vector Aedes aegypti. Esto alertó tanto a las autoridades como a los medios de comunicación.

La distribución total por medio de comunicación y tema se puede observar en el Gráfico 9.

\section{Tema información científica por medio de comunicación}

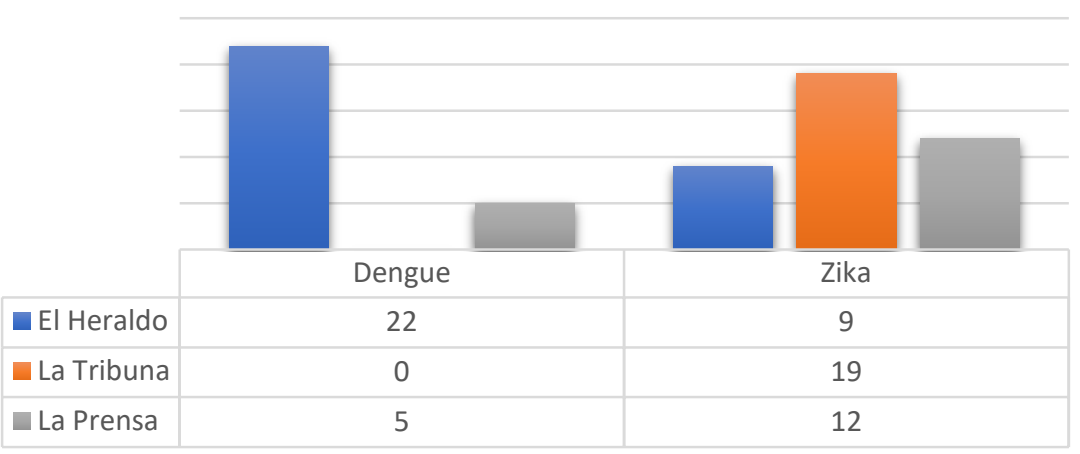

Gráfico 9. Distribución de publicaciones por tema según el medio de comunicación. Fuente: elaboración propia.

Como se describió en el Gráfico 4, la información relacionada sobre evidencia científica dentro de este análisis de contenido dentro de los tres medios de comunicación en los 8 años de análisis fue de un $\mathbf{2 7 \%}$. El registro de esta información fue en base a publicaciones relacionadas con estudios, datos y método científico. La gráfica representada en el Gráfico 10, muestra que el $76 \%$ de las publicaciones fue información sobre datos, el $16 \%$ correspondió a estudios científicos y el $8 \%$ a temas que explicaban métodos científicos.

\footnotetext{
${ }^{8}$ Según DA CUNHA, (1872), no se puede rastrear la fiebre del dengue en las escrituras de los antiguos griegos y romanos. La enfermedad no existía en su tiempo o se confundía 'con exageraciones'. Sin embargo, es considerada -según el autor- tan antigua como la viruela.
} 


\section{Total de noticias con información científica}

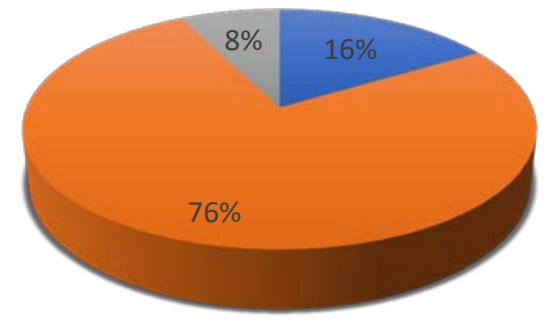

Estudios Datos Método Científico

Gráfico 10. Distribución porcentual de los encuadres de la información científica a nivel general. Fuente: elaboración propia.

La distribución de estas temáticas abordadas por medio de comunicación se ve representada en el Gráfico 11 que corresponde al número total de notas publicadas por diario en los 8 años según la semana construida. A nivel global, es decir, por tema tratado, la representación por medio de comunicación sobre estos encuadres (datos, estudios y método científico) se distribuyó de la siguiente manera: El Heraldo, con un 46\%; La Tribuna, con un 28\%; y La Prensa, con un $25 \%$.

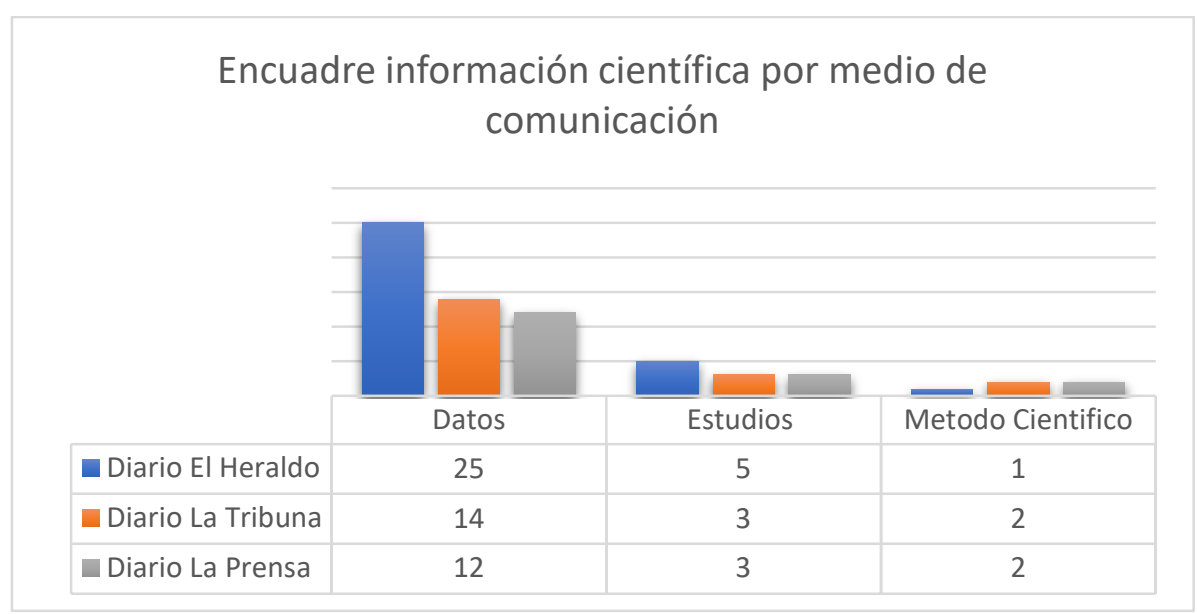

Gráfico 1. Distribución del encuadre de la información científica por medio de comunicación. Fuente: elaboración propia.

La mayoría de estas publicaciones, como se mostró en las gráficas anteriores, correspondieron a 'datos'. Esta información -en su mayoría- trató sobre aumento o reducción del número de casos según las semanas epidemiológicas que la Secretaría de Salud de Honduras venía recopilando. También, información sobre los casos clínicos reportados y por confirmar a nivel nacional y, los datos recopilados por la OMS y la OPS.

Esto también viene relacionado a que, el origen de estas publicaciones en un $73 \%$ correspondieron a declaraciones emitidas por las autoridades sanitarias y gubernamentales del país y el $27 \%$ fueron datos emitidos por entes internacionales, ver Gráfico 12. 


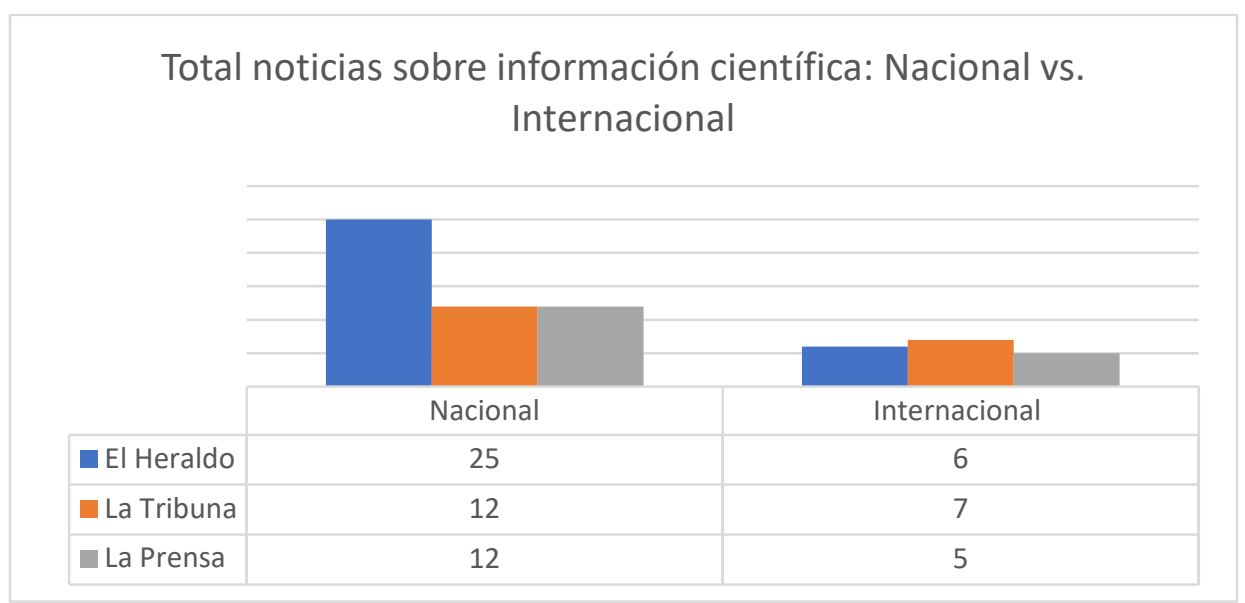

Gráfico 12. Distribución de publicaciones según su origen por medio de comunicación. Fuente: elaboración propia.

Estas publicaciones internacionales, en su mayoría correspondieron a los estudios que se publicaron en revistas científicas y que luego las grandes cadenas de comunicación como ser la estadounidense (The New York Times) y las europeas (ACAN/EFE) trabajaron para su divulgación. Estas serían "transcritas" por los medios de comunicación analizados. Otros datos también correspondían a las investigaciones realizadas por la OMS y la OPS, cuyos datos también fueron publicados en sus portales en Internet o conferencias de prensa.

Los indicadores lingüisticos: La correlación en cuanto al indicador lingüístico en la redacción del titular consistió en primer lugar, para comprender cómo los medios de comunicación utilizados como objeto de estudio, titularon durante estos 8 años las informaciones correspondientes a las patologías dengue y zika. Es a través del titular que el lector muestra interés respecto a una información.

La distribución de los indicadores lingüísticos seleccionados en la ficha de registros a nivel porcentual se representa de la siguiente manera: alarmante $2 \%$, brote $0 \%$, casos $20 \%$, epidemia $3 \%$, fallecimiento $0 \%$, muerte $9 \%$, emergencia $2 \%$, virus $1 \%$, propagación $1 \%$, combatir $6 \%$, alerta $3 \%$ y otros indicadores $52 \%$. En el Gráfico 13 se muestra el total de noticias según el indicador lingüístico.

Si bien, como se señaló anteriormente, un 52\% de las noticias (129 noticias) no presentó los indicadores determinados dentro de la ficha de registro formulada. Sin embargo, el otro número notable dentro de la muestra corresponde al indicador 'casos' con un 20\% (50 noticias). Su relación en la narrativa de la noticia se vinculó a las semanas epidemiológicas con las que las autoridades sanitarias informaron sobre el posible aumento o reducción de las personas infectadas con los virus dengue y zika.

En el Gráfico 4, se pudo apreciar que la distribución de los encuadres de la noticia destacó la 'atribución de responsabilidades' (23\%) y 'políticas sanitarias' $(17 \%)$, temáticas orientadas a la lucha contra el vector transmisor de las enfermedades. Esto también vincula la aparición del indicador 'combatir' en un $6 \%$ de las publicaciones que correspondió a 14 noticias, de las cuales en su mayoría fueron publicadas por diario La Tribuna. 
Dentro del análisis del indicador lingüístico, también se identificó que fueron escasas las noticias que se publicaron con titulares que contuvieran una terminología especializada o referente a los temas de salud. Es decir, los indicadores 'epidemia' (3\%) y 'virus' (1\%), tuvieron una aparición en 8 y 2 noticias respectivamente, dentro de la muestra analizada. Otros de los indicadores que tuvieron un bajo número representativo en los titulares fueron 'emergencia' (2\%), 'propagación' (1\%) con 5 y 2 noticias publicadas.

Las situaciones por destacar sobre las noticias recolectadas es que, en su gran mayoría, los indicadores tuvieron una relación sensacionalista o extremista. Por ejemplo: un total del 9\% (23 noticias) correspondió a información con el indicador 'muerte' en su titular, siendo los diarios El Heraldo y La Prensa los que más utilizaron el término. Los otros indicadores como 'alarmante' (4 noticias) y 'alerta' (3 noticias) tuvieron una aparición de $2 \%$ y $3 \%$ en los titulares de las noticias de los tres medios utilizados como objeto de estudio. El Gráfico 14 muestra la distribución de los indicadores lingüísticos por diario.

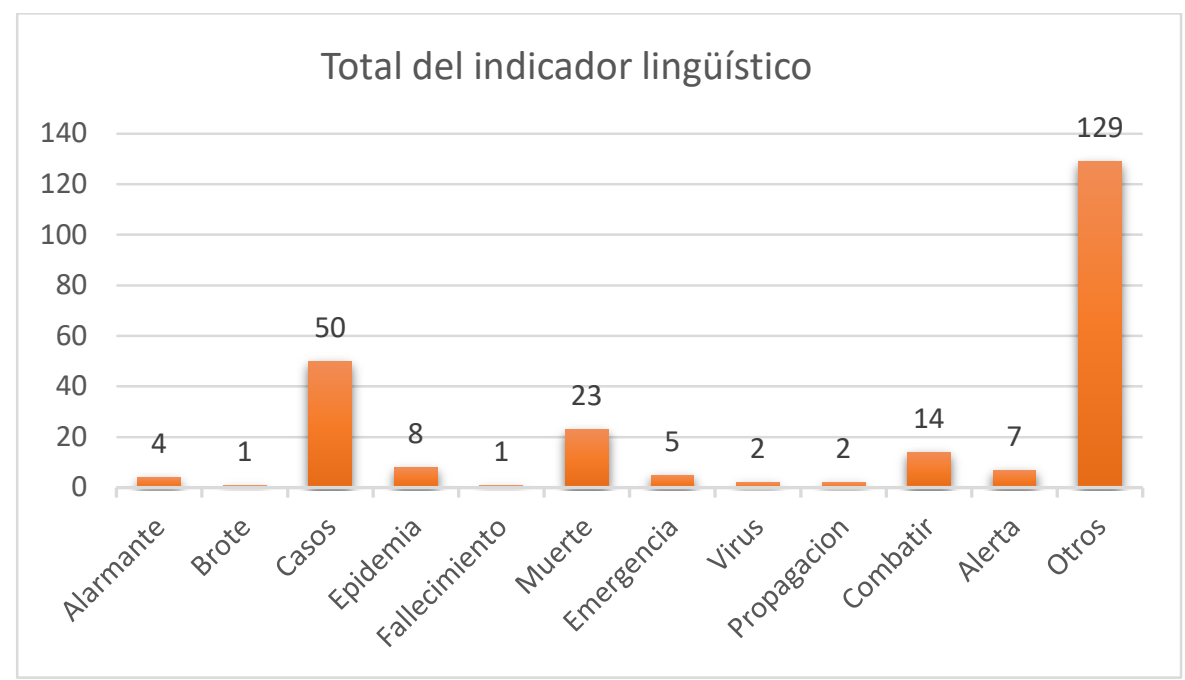

Gráfico 13. Distribución total del indicador lingüístico. Fuente: elaboración propia

\section{Total indicador lingüístico por medio de comunicación}

\begin{tabular}{|c|c|c|c|c|c|c|c|c|c|c|c|c|}
\hline & $\ldots$ & & & $\square$ & & 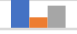 & - & & & 2 & 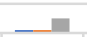 & \\
\hline & $\begin{array}{c}\text { Alarm } \\
\text { ante }\end{array}$ & Brote & Casos & $\begin{array}{c}\text { Epide } \\
\text { mia }\end{array}$ & $\begin{array}{c}\text { Falleci } \\
\text { mient } \\
0\end{array}$ & $\begin{array}{c}\text { Muer } \\
\text { te }\end{array}$ & $\begin{array}{c}\text { Emer } \\
\text { genci } \\
a\end{array}$ & Virus & $\begin{array}{c}\text { Propa } \\
\text { gacio } \\
n\end{array}$ & $\begin{array}{c}\text { Comb } \\
\text { atir }\end{array}$ & Alerta & Otros \\
\hline E El Heraldo & 1 & 1 & 17 & 7 & 1 & 11 & 3 & 0 & 1 & 3 & 1 & 57 \\
\hline La Tribuna & 2 & 0 & 22 & 1 & 0 & 4 & 2 & 1 & 0 & 10 & 1 & 43 \\
\hline - La Prensa & 1 & 0 & 11 & 0 & 0 & 8 & 0 & 1 & 1 & 1 & 5 & 29 \\
\hline
\end{tabular}


Gráfico 14. Distribución del Indicador Lingüístico por medio de comunicación. Fuente: elaboración propia.

Como se indicó al inicio del apartado 'los encuadres lingüísticos', la influencia de otros indicadores fue más representativo en el análisis de contenido (el $52 \%$ ). Estos datos, al ser tan variados no se pueden cuantificar e identificar dentro de un gráfico. Sin embargo, estos estuvieron orientados de igual manera al fomento de la prevención y siguieron una frecuencia de aparición en los tres medios de comunicación.

Entre estos, se puede deducir que, diario El Heraldo utilizó indicadores relacionados a la prevención, la lucha, las víctimas, el contagio, y las emergencias. Por su parte, diario La Tribuna utilizó indicadores relacionados a medidas de prevención, la lucha, la recomendación, la aparición y la infección; y, el diario La Prensa utilizó indicadores relacionados con la campaña, las medidas, el afectado, la víctima, y la fumigación; entre otros.

Es decir, que las noticias relacionadas con estas patologías fueron tituladas con indicadores sensacionalistas, que muestran que no hubo una cuasi especialización en cuanto a la proyección social para transmitir la información rigurosa que sería conveniente para hacer llegar a la población con respaldo científico. (Ver Anexos)

\section{Conclusiones}

Los resultados de esta investigación enmarcada en la teoría de la agenda setting y en la que se ha valorado la especialización de las noticias por el contenido clínico específico, son los siguientes:

Se determina que los medios de comunicación digital en Honduras atienden a la agenda setting con criterios de actualidad, polémica e interés público. Sin embargo, se obvia las bases de un periodismo especializado. Tal es el caso del periodismo científico, la comunicación de la medicina y temas de salud. Estos temas no cuentan en los medios de comunicación analizados, siquiera con una sección de identificación dentro de los portales web.

Que existe un desinterés y poca especialización en aprovechar la inmediatez y facilidad de espacio que favorece el periodismo digital. Su uso como herramientas de educación, información y profundizar temas que en los impresos no son posibles, se ven desaprovechados. La información periodística sobre estas patologías muestra una evidente escasez de publicaciones dentro de los 8 años correspondientes para el estudio. Es por esta razón la inexistente divulgación de publicaciones referentes al dengue como primera epidemia presente en el país y las alarmantes publicaciones sobre el zika.

Analizando la muestra, se determinó que durante los años 2010-2013 (4 años de análisis), fueron casi nulas las publicaciones referentes al dengue. Dentro de esos años se comienza a decretar la alerta en el país de una nueva epidemia de dengue, sin embargo, las noticias dentro y fuera de la semana construida, son escasas. Estos años vacíos, quedan abiertos para futuras investigaciones que evidencien el porqué de la falta de información. En ese sentido, se concluye que estos tres medios digitales comenzaron a informar sobre estas patologías a partir del 2014. La relación de estos datos coincide con la propagación de los brotes del chikungunya (2014) y el zika (finales del 2015). 
Tras los repuntes de casos de pacientes afectados por estas patologías, los encuadres noticiosos estuvieron ligados a temáticas sobre la atribución de responsabilidades (el 23\%), la implementación de políticas públicas a nivel nacional (el 17\%) ligadas a las ordenanzas municipales. Este papel de prevención a la población fue trabajado por los tres medios de comunicación tras las frecuentes declaraciones dadas por las autoridades de administración sanitaria (el $73 \%$ ). Y en última instancia, a los datos emitidos por las organizaciones internacionales (el 27\%), como la OMS y OPS.

Al igual que los encuadres de la noticia, la orientación de los titulares, coinciden en similitud de número de publicaciones. Estos indicadores lingüísticos estuvieron relacionados a: 'casos', (el 20\%); 'combatir', (el 6\%); y 'muerte', (el 9\%). No obstante, el alto porcentaje de los indicadores lingüísticos correspondieron a otro tipo de términos utilizados por los medios en sus titulares (el $52 \%$ ), que de igual manera se orientaron al fomento de la prevención.

Dentro de la muestra analizada, en su gran mayoría de las publicaciones tuvieron encuadres sobre "información científica", pero esta fue en torno a datos estadísticos emitidos por las autoridades sanitarias, demostrando más evidencia sobre la falta de una especialización que permita al periodista profundizar más en temas de salud y de riesgo epidémico. Mientras que las publicaciones sobre estudios e investigaciones correspondieron a publicaciones internacionales, de consulta a medios de las grandes cadenas de comunicación internacional. Destacando que los diarios La Tribuna y La Prensa dieron mayor realce a temas sobre el zika, (el $60 \%$ ). Mientras que El Heraldo se focalizó en la información científica sobre el dengue, (el 40\%).

Aunque en Honduras existan artículos científicos publicados en revistas de ciencia nacional e internacional, sobre las epidemias de dengue que enfrentó el país en el siglo XX. El evidente trabajo de estudios científicos sobre el zika realizados partir del 2016. Resulta preocupante que ninguno de los medios seleccionados como muestra hayan trabajado sobre tales estudios y en segunda instancia, consultado a los investigadores involucrados para la generación de información sobre estas patologías.

El análisis general sobre los encuadres de las noticias y los actantes dentro de las mismas, concluyen que los datos estadísticos son expuestos por las autoridades sanitarias y gubernamentales, pero no conllevan una explicación en profundidad por un especialista. No es evidente la inclusión de la opinión de epidemiólogos e investigadores de la academia y el uso de términos en sus titulares para referir sobre los hechos van más allá de lo que la situación amerita.

Sería interesante, tras los resultados obtenidos enrolar a los medios de comunicación para que dieran el paso a participar en la elaboración de noticias a un mayor número de los investigadores y de médicos especializados, para abordar el tratamiento informativo sobre esta temática desde el punto de vista del origen, la propagación y el riesgo.

Es necesario e imprescindible que los medios de comunicación digital de un país como Honduras, cuya geografía, clima y situación socioeconómica, favorece a alta frecuencia de vectores que propagan epidemias graves, se dediquen a la investigación sobre estas patologías, ahonden más el interrogatorio y la curiosidad de la historia, origen, afectaciones y terminologías sobre dichas enfermedades. 
En cuanto a las limitaciones del estudio, podemos destacar que el universo de documentos y la muestra seleccionada para su análisis puede presentar un error muestral y además ser escaso el número de unidades seleccionadas para el estudio. En cualquier caso, se considera que los datos obtenidos son un indicador para poder observar grandes líneas de trabajo de cada uno de los diarios analizados, así como sus tendencias en cuanto a la difusión de información sobre el dengue y el zika. No obstante, se alcanzó un $65 \%$ de la muestra y se logró identificar y responder algunas preguntas estipuladas a lo largo del trabajo. Entre ellas, se ha logrado concluir que el periodismo digital de Honduras no se centra en divulgar en profundidad sobre las epidemias que "atacan" al país, como el dengue y el zika. 


\section{Referencias bibliográficas}

ALMEIDA, C.; RAMALHO, M.; BUYS, B.; MASSARANI, L., (201). "La cobertura de la ciencia en América Latina: estudio de periódicos de élite en nueve países de la región", En: Periodismo y Divulgación Científica. Tendencias En El Ámbito Iberoamericano. Biblioteca Nueva, S. L., Madrid, pp. 75-97.

BERMÚDEZ-MADRIZ, J.L.; MUISER, J., 2011. Sistema de salud de Honduras. Salud Pública México 53, 11.

CALVO HERNANDO, M., (2011). "De la divulgación científica a la ciencia mediática", En: Periodismo y Divulgación Científica. Tendencias En El Ámbito Iberoamericano. Biblioteca Nueva, S. L., Madrid, pp. 16, 18, 29.

DA CUNHA, J. G., (1872). Dengue, its history, symptons and treatment; with observations on the epidemic wich prevailed in Bombay during the years 1871-72.

DE SEMIR, V., (1996). "¿Qué hechos merecen ser noticia?". En: The Lancet 17-23.

DICK, G.W.; KITCHEN, S.; HADDOW, A., (1952). "Zika Virus (I). Isolations and serological specificity". Trans. R. Soc. Trop. Med. Hyg. 46, 509-520. https://doi.org/10.1016/00359203(52)90042-4

DICKSON, H., (1839). On Dengue: it's history, pathology and treatment.

Evaluación Rápida del Riesgo de transmisión de enfermedad por el virus zika en España, 2015.

HAGEN, L.; KELLER, T.; NEELY, S.; DEPAULA, N.; ROBERT-COOPERMAN, C., (2017). "Crisis Communications in the Age of Social Media: A Network Analysis of Zika-Related Tweets". Soc. Sci. Comput. Rev. 089443931772198.

https://doi.org/10.1177/0894439317721985

HAYES, E.B., (2009). "Zika Virus Outside Africa". Emerg. Infect. Dis. 15, 1347-1350. https://doi.org/10.3201/eid1509.090442

HESTER, J.B.; DOUGALL, E., (2007). "The efficiency of constructed week sampling for content analysis of online news". JMC Q. 84, 811-824.

IGARTUA, J.J.; HUMANES, M.L., (2004). "El método científico aplicado a la investigación en comunicación social". Portal Comun. InCom-UAB 18.

LÓPEZ NOGUERO, A., (2002). "El análisis de contenido como método de investigación". Rev. Educ. 167-179.

MONTES, M.; ESCALANTE, H., (2010). "Aspectos epidemiológicos, clínicos y de gestión del sistema de salud ante la epidemia del dengue, Honduras, 2010". Rev. Fac. Cienc. Médicas 7, 17-26.

MORENO CASTRO, C., (2009). "Comunicar los Riesgos. Ciencia y Tecnología en la Sociedad de la Información". Madrid: Biblioteca Nueva/OEI 
NÚÑEZ, E.; VÁSQUEZ, M.; BELTRÁN-LUQUE, B.; PADGETT, D., (2016). "Virus Zika en Centroamérica y sus complicaciones" 8.

Oliver, S.E., Paúls, B.G., 2014. El encuadre de los temas de salud: cobertura en prensa escrita del daño cerebral adquirido 17.

Plan Mesoamericano de gestión integrada para la prevención y control del Dengue y Chikungunya 2016-2017, Honduras, 2016.

RAMÍREZ, M.I.S.; QUESADA, M.Q.; HERNÁNDEZ, I.G., (2010). "Knowledge, attitudes and practices against the dengue fever promoted by Costa Rican media" 19, 5 .

RAPPA, M.; HEALEY, C.G.; VILLANES, A.; GRIFFITHS, E., (2018). "Dengue Fever Surveillance in India Using Text Mining in Public Media". En: Am. J. Trop. Med. Hyg. 98, 181-191. https://doi.org/10.4269/ajtmh.17-0253

RIBEIRO, J.C., (2013). "Propuesta metodológica para el análisis de blogs periodísticos. Intercom". En: Rev. Bras. Ciênc. Comun. 36, 197-218. https://doi.org/10.159o/S18og58442013000200010

ROSALES, A.; YEPES-MAYORGA, A.; ARIAS, A.; FRANZ, F.; THOMAS, J.; HUDDLE, J.; SOTO, R.J.; HAYNES, M.; PRADO, M.; CHERIAN, D., (2017). "A cross-sectional survey on ZIKV in Honduras: Implications for governance and risk communication approaches". En: Int. J. Health Gov. 22, 83-92. https://doi.org/10.1108/IJHG-11-2016-0053

SAMUDIO BARRIOS, S., (2016). "Science journalism: Prospects and challenges in Paraguay". En: Rev. Int. Investig. En Cienc. Soc. 12, 223-238.

https://doi.org/10.18004/riics.2016.diciembre.223-238

SANZ MERINO, N., (2011). "La perspectiva CTS en el estudio y reflexión sobre la comunicación social de la ciencia y la tecnología", En: Periodismo y Divulgación Científica. Tendencias En El Ámbito Iberoamericano. Biblioteca Nueva, S. L., Madrid, pp. 42, 47, 48.

Special Programme for Research and Training in Tropical Diseases, World Health Organization (Eds.), 2009. Dengue: guidelines for diagnosis, treatment, prevention, and control, New ed. ed. TDR: World Health Organization, Geneva.

ZAVALA, G. L., (2010). "Dengue y Vigilancia". En: Rev. Fac. Cienc. Médicas 7, 7-8. 
ANEXOS

Otros

El Heraldo

\begin{tabular}{l|l|l}
\hline Prevenir & Lucha & Ordenanzas \\
\hline Extensión & BTI & Plan Estratégico \\
\hline Debe Saber & Serotipo Den 3 & Calamitosa \\
\hline Repelentes Caseros & Vacuna & Exámenes \\
\hline Miedo & Repunta & Insumos \\
\hline Promoción & Síntomas & Ataque \\
\hline Eliminar & Presencia & Cobros \\
\hline Detección & Auditoría & Eliminar \\
\hline Promover & Dolores & Dona \\
\hline Tienen & Control de Medicinas & Sin Capacidad \\
\hline Vacuna & Atacan & Cobrar Vidas \\
\hline Oleada & Campaña & Contagiadas \\
\hline Investigarán & Índice & Espacios Libres \\
\hline Pruebas & Resistencia & Fumigan \\
\hline Aumento & Operativo & Refuerzan \\
\hline Interviene & Serotipo Den 4 & Víctima \\
\hline Fumigan & Preocupa & Elevado Gasto \\
\hline & & \\
\hline
\end{tabular}

\section{Otros}

La Prensa

\begin{tabular}{l|l|l}
\hline Fumigan & Trabajo Organizado & \\
\hline Teoría & Ofensiva & Campaña \\
\hline Intensifican & Acciones & Medidas \\
\hline Afectado & Operativo & Hiperendemia \\
\hline Enfermos & Protegen & Saturados \\
\hline Labor & Víctima & Problemas Neurológicos \\
\hline Reportan & Vigilancia & \\
\hline Invento & Suman Contra & \\
\hline Medidas & Aumentan & \\
\hline Infección & Potenciar & \\
\hline
\end{tabular}


- Laura Aceituno Castillo

Otros:

La Tribuna

\begin{tabular}{|l|l|l}
\hline Recomendación & Entregar Presidencia & Detectaron \\
\hline Lucha & Campaña & Nacen \\
\hline Matar & Fumigan & Habilitan \\
\hline Aborto Terapéutico & Detectaron & Criadero \\
\hline Zancudos & Aumentan & Pruebas de Muerte \\
\hline Aparición & Operativo & $\begin{array}{l}\text { Cerco } \\
\text { Epidemiológico }\end{array}$ \\
\hline Aclaración & Atacan & Infectado \\
\hline Incremento & Batalla & Prevenir \\
\hline Hallazgo & Saturados & Identifican \\
\hline Promoción & Guerra & \\
\hline Lucha & Medicamentos & \\
\hline Caída Turismo & Descartan & \\
\hline
\end{tabular}

